\title{
Variação no rendimento e composição química do óleo essencial de folhas de atroveran (Ocimum selloi Benth.) inteiras e moídas sob condições de armazenamento
}

\author{
COSTA, L.C.B. ${ }^{1 *}$; PINTO, J.E.B.P. ${ }^{2}$; BERTOLUCCI, S.K.V. ${ }^{2}$; ALVES, P.B. ${ }^{3}$; EVANGELINO, T.S. ${ }^{3}$ \\ 1UESC, Depto. de Ciências Biológicas, 45662-000, Ilhéus, BA. *larissa@uesc.br; ${ }^{2} U F L A$, Depto. de Agricultura, \\ 37200-000, Lavras, MG; 3UFS, Depto. de Química, 49100-000, São Cristovão, SE.
}

\begin{abstract}
RESUMO: Além das características genéticas e ambientais, o sistema de cultivo e processamento das plantas medicinais também são fatores importantes para a determinação da qualidade final do produto. Entre estes está o armazenamento, sobre o qual há poucas informações a respeito da conservação de plantas medicinais. Este trabalho teve como objetivo estudar o efeito do tempo de armazenamento sobre o rendimento e a composição química do óleo essencial na biomassa seca de folhas inteiras e moídas de Ocimum selloi. O experimento constou de dois tratamentos de fragmentação (folha inteira e moída) e cinco tempos de armazenamento $(0,3,6$, 9 e 12 meses). A biomassa seca foi embalada emsaquinhos de polipropileno lacrados e armazenada em local seco e escuro. O óleo essencial foi extraído pelo processo de hidrodestilação em aparelho tipo Clevenger modificado e sua composição química foi analisada por cromatografia gasosa com detector de ionização de chama (FID) acoplada à espectrometria de massa (CGEM). Ocorreu uma redução acentuada no rendimento de óleo essencial da biomassa seca armazenada de folhas inteiras e moídas ao longo de umano de armazenamento, mas o rendimento obtido a partir de folhas inteiras foi significativamente superior ao das folhas moídas. De uma forma geral, durante todo o período avaliado, o metil-chavicol, composto majoritário, esteve presente com uma maior concentração relativa nas folhas inteiras do que nas folhas moídas, apresentando um comportamento de decréscimo ao longo do tempo de armazenamento. $O$ tipo de fragmentação e o tempo de armazenamento interferem decisivamente no rendimento e na composição do óleo essencial de $O$. selloi.
\end{abstract}

Palavras-chave: Ocimum selloi Benth., plantas medicinais, pós-colheita, óleo essencial, metilchavicol

\begin{abstract}
Variation in essential oil yield and chemical composition of whole and powdered "atroveran" (Ocimum selloi Benth.) leaves under storage conditions. Besides genetic and environmental characteristics, the cultivation and processing systems of medicinal plants are important factors in the product final quality. Among such factors, storage has been scarcely studied regarding medicinal plant conservation. The aim of this work was to study the effect of storage time on essential oil yield and chemical composition in the dry matter of whole and powdered Ocimum selloi leaves. The experiment consisted of two fragmentation treatments (whole and powdered leaf) and five storage times (0, 3, 6, 9, and 12 months). Dry leaves were packed in plastic bags, which were sealed and stored in a dry and dark place. The essential oil was extracted by hydrodistillation in modified Clevenger-type device and the chemical composition was analyzed through gas chromatography using a flame ionization detector attached to a mass spectrometer (GC-MS-FID). There was an accentuated reduction in the essential oil yield of powdered and whole leaves stored over one year, but the essential oil yield of whole leaves was significantly higher than that of powdered ones. In general, the major compound methyl-chavicol was higher in whole leaves than in powdered ones and decreased over the storage time. The fragmentation type and the storage time decisively interfere in $O$. selloi essential oil yield and composition.
\end{abstract}

Key words: Ocimum selloi Benth., medicinal plants, post-harvest, essential oil, methyl-chavicol

Recebido para publicação em 22/11/2007

Aceito para publicação em 07/07/2008

Rev. Bras. PI. Med., Botucatu, v.11, n.1, p.43-48, 2009. 


\section{INTRODUÇÃO}

Ocimum selloiBenth. (Lamiaceae) é uma espécie nativa das regiões sul e sudeste do Brasil, encontrada em estado silvestre ou cultivada em hortas e quintais residenciais conhecida popularmente como elixir-paregórico, alfavaquinha ou atroveran (Lorenzi \& Matos, 2003). Popularmente é usada como antidiarréico, antiespasmódico e antiinflamatório, além da sua atividade como repelente de insetos já comprovada cientificamente (Paula et al., 2003).

Para obtenção de um produto final de excelente qualidade a partir de plantas medicinais, diversos fatores são importantes: identificar a espécie, colher o órgão vegetal correto no estágio de crescimento adequado, oferecer condições ótimas de cultivo (solo, luz, água e temperatura), secar e armazenar o produto sob temperatura e condições que evitem a redução dos teores de fitoquímicos e utilizar a técnica de extração mais apropriada (Tanko et al., 2005). O beneficiamento das plantas medicinais varia de acordo com a forma de comercialização, entretanto a grande maioria é vendida na forma desidratada, tornando o processo de secagem fundamental para a qualidade final do produto. A secagem visa impedir a deterioração do material por meio da redução do teor de água, atuando negativamente na ação das enzimas pela desidratação. A redução do teor de umidade também faz com que a atividade das enzimas seja diminuída, prevenindo a perda de qualidade das plantas quanto mais rapidamente for realizada (Martins et al., 1995). Para prevenir a deterioração do produto durante o período de armazenamento, deve-se controlar a umidade e a temperatura do ar, bem como o ataque de insetos, roedores e microrganismos (Tanko et al., 2005).

Apesar de ser evidente que o período de armazenagem deve ser o menor possível para reduzir ao máximo as perdas de princípios ativos, há escassez de informações à respeito do prazo máximo de conservação de plantas medicinais secas, por isto é importante que se conheça bem o comportamento de cada espécie durante a fase de armazenamento (Martins et al., 1995). Até mesmo na América do Norte a "vida de prateleira" de drogas vegetais parece ser arbitrária. Falta a realização de testes de estabilidade em lotes individualizados de material vegetal como já é feito compílulas e outros medicamentos alopáticos. Como os medicamentos à base de plantas são produzidos emgrandes quantidades e devem ser transportados para distribuição, não se sabe quanto tempo estas plantas já estavam estocadas e, portanto quão efetivo será o tratamento (Griggs et al., 2001).

As perdas de princípios ativos que ocorrem após a colheita devem-se a várias razões, dentre elas, a degradação por processos metabólicos, hidrólise, degradação pela luz, enzimática, oxidação, fermentação, calor e contaminação microbiológica (Silva et al., 1999). Apesar disto, a maior parte dos trabalhos de conservação póscolheita complantas medicinais estudam apenas os tipos de embalagens e a qualidade microbiológica do material armazenado (Silva et al., 1999; Costa et al., 1999a; Costa et al., 1999b) sem, contudo verificar as possíveis variações nos teores de princípios ativos remanescentes na matéria seca.

Este trabalho teve como objetivo avaliar o efeito do tempo de armazenamento sobre a variação quantitativa e qualitativa do óleo essencial presente na biomassa seca de folhas inteiras e moídas de $O$. selloi.

\section{MATERIALE MÉTODO}

\section{Localização}

O trabalho foi conduzido no Horto de Plantas Medicinais do Departamento de Agricultura (DAG) da Universidade Federal de Lavras (UFLA) em Lavras, município situado na região Sul do Estado de Minas Gerais, a $918,87 \mathrm{~m}$ de altitude, latitude $21^{\circ} 14^{\prime} \mathrm{S}$ e longitude $45^{\circ} 00^{\prime}$.

\section{Cultivo das plantas}

Sementes de atroveran (Ocimum selloi Benth.) depósito herbário ESAL n 7474 determinado por P. Albuquerque, foram plantadas em bandejas de poliestireno expandido de 72 células preenchido com substrato comercial Plantmax ${ }^{\circledR}$ e mantidas em casa de vegetação sob nebulização intermitente por 60 dias. As mudas foram transplantadas para o campo em terreno previamente arado e adubado com 0,5 L de esterco de gado curtido por cova em espaçamento $0,6 \times 0,6 \mathrm{~m}$. Nos primeiros meses de estabelecimento foi mantida irrigação diária e capinas freqüentes foram realizadas conforme a necessidade.

\section{Beneficiamento e armazenamento}

Após 150 dias, 144 plantas foram colhidas às 8:00 horas da manhã para secagem das folhas em estufa com circulação de ar forçada a 35ํㅡ, até peso constante, constituindo uma amostra composta.

O experimento constou de dois tratamentos de fragmentação (folha inteira e moída em moinho de facas utilizando tamis commalha de 20 mesh) e cinco tempos de armazenamento (0, 3, 6, 9 e 12 meses). A biomassa seca inteira e moída foi embalada individualmente em saquinhos de polipropileno lacrados contendo 40 gramas de material e armazenada em local seco e escuro com temperatura média de $25^{\circ} \mathrm{C}$. 


\section{essencial}

\section{Extração e quantificação do óleo}

Para a avaliação do rendimento de óleo essencial nos diferentes tempos de armazenamento, o óleo foi extraído pelo processo de hidrodestilação em aparelho tipo Clevenger modificado com $40 \mathrm{~g}$ de matéria seca, balão de fundo redondo de $1000 \mathrm{~mL}$ contendo $500 \mathrm{~mL}$ de água destilada por 90 minutos. Em seguida, realizou-se uma partição líquido-líquido, em funil de separação, no qual foi adicionado diclorometano ao hidrolato para a extração do óleo. À fração orgânica obtida adicionou-se sulfato de magnésio anidro em excesso para retirar possíveis resíduos de umidade. O sal foi removido por filtração simples e o filtrado foi mantido à temperatura ambiente sob capela de exaustão de gases em vidros escuros tampados com papelalumínio perfurado para permitir a evaporação do restante do solvente. Em seguida, foram determinadas as massas dos óleos obtidos para cálculo do rendimento $\left(\mathrm{g} \mathrm{kg}^{-1}\right.$ biomassa seca).

\section{Análise química do óleo essencial}

A análise da composição química do óleo essencial foi realizada no Laboratório de Cromatografia do Departamento de Química da Universidade Federal de Sergipe, por meio de uma amostra composta pela reunião dos óleos essenciais das seis repetições de cada tratamento.

\section{Cromatografia gasosa (CG-FID)}

As análises por cromatografia gasosa utilizando equipamento Shimadzu 17 Aequipado com detector de ionização de chama (FID), sob as seguintes condições: vazão de $1 \mathrm{~mL} / \mathrm{min}$ de hélio como gás de arraste; temperatura do injetor de $250^{\circ} \mathrm{C}$; temperatura do detector (FID) $280^{\circ} \mathrm{C}$, o programa de temperatura da coluna foi $50^{\circ} \mathrm{C}-200^{\circ} \mathrm{C}$ a uma taxa de $4^{\circ} \mathrm{C} \mathrm{min}^{-1}$ então aquecendo para $300^{\circ} \mathrm{C}$ a $10^{\circ} \mathrm{C} \mathrm{min}^{-1}$ e mantendo esta temperatura constante por $10 \mathrm{~min}$. Uma coluna capilar de sílica fundida com fase estacionária DB-5MS (30 m x 0,2 mm x 0,25 $\mu \mathrm{m}$ de espessura de filme) foi utilizada.

\section{Cromatografia Gasosa - Espectrometria de Massas (CG-EM)}

Nas análises por cromatografia gasosa acoplada à espectrometria de massa (CG-EM), foi utilizado um equipamento Shimadzu QP5050A equipado com um analisador do tipo quadrupo. As condições cromatográficas foram: coluna capilar de sílica fundida comfase estacionária DB-5MS (30 mx $0,2 \mathrm{~mm} \times 0,25 \mu \mathrm{m}$ de espessura de filme). Nas análises por CG-EM foi utilizado He (99.999\%) como gás de arraste com vazão de 1,2 $\mathrm{mL}^{\mathrm{min}^{-1}}$, a temperatura foi programada mantendo $50^{\circ} \mathrm{C}$ por 1,5 min, aumentando para $200^{\circ} \mathrm{C}$ a $4^{\circ} \mathrm{C} \mathrm{min}^{-1}$, então aquecendo para $300^{\circ} \mathrm{C}$ a $10^{\circ} \mathrm{C}$ min $^{-1}$ e mantendo esta temperatura constante por $10 \mathrm{~min}$; as temperaturas da fonte e da interface foram $250^{\circ} \mathrm{C}$ e $280^{\circ} \mathrm{C}$, respectivamente; o volume de injeção foi $0,2 \mu \mathrm{L}$ da solução (50 mg do óleo diluídos em $2 \mathrm{~mL}$ de acetato de etila) com velocidade de arraste de $1,5 \mathrm{~mL} \mathrm{~min}^{-1}$.

Os espectros de massas foram obtidos por impacto eletrônico de $70 \mathrm{eV}$. A velocidade de varredura

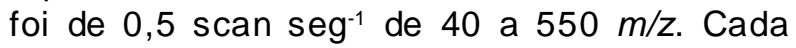
componente foi identificado através da comparação do seu espectro de massas comespectros existentes na literatura (Adams, 2007) e pela comparação computadorizada do espectro de massas com o banco de dados da biblioteca NIST e outros espectros de massas publicados (Van Den Dool \& Kratz, 1963).

Os índices de retenção (IK) foram determinados paratodos os constituintes voláteis emrelação aos tempos de retenção da série homóloga de $n$-alcanos $\left(\mathrm{C}_{8}-\mathrm{C}_{18}\right)$. $\mathrm{A}$ concentração relativa dos componentesforam calculadas pelo método de normalização da área, sem considerar o fator de resposta.

\section{Análise estatística}

O delineamento experimental adotado foi o inteiramente casualizado com quatro repetições. Os dados obtidos foram submetidos à análise estatística utilizando comparação de médias através do teste $F$ a $5 \%$ de probabilidade para o tipo de fragmentação do material vegetal e análise de regressão, para o tempo de armazenamento.

\section{RESULTADO E DISCUSSÃO}

O rendimento de óleo essencial obtido a partir de folhas inteiras foi significativamente superior ao obtido das folhas na forma de pó com uma média geral durante todo o período de armazenamento de 13,15 e 9,88 $\mathrm{g} \mathrm{kg}^{-1}$, respectivamente. Estudos realizados com Cymbopogon citratus apresentaram resultado oposto com maior rendimento de óleo essencial obtido na biomassa seca reduzida a pó, quando comparada aos fragmentos maiores (Costa et al., 2005). Este comportamento pode ser explicado pela diferente localização histológica das estruturas secretoras. Em C. citratus são células parenquimáticas, enquanto em $O$. selloi os tricomas glandulares permanecem mais preservados nas folhas inteiras garantindo maior rendimento de óleo nesta condição. Além disso, considerando-se o tempo de armazenamento, a biomassa seca na forma de pó possui maior superfície de exposição permitindo uma maior perda dos óleos essenciais.

O rendimento de óleo essencial apresentou uma resposta quadrática em relação ao tempo de armazenamento, sendo observada uma redução acentuada no período avaliado. Quatro meses de armazenamento da biomassa seca na forma inteira e moída foramsuficientes para reduzir cerca de $50 \%$ 


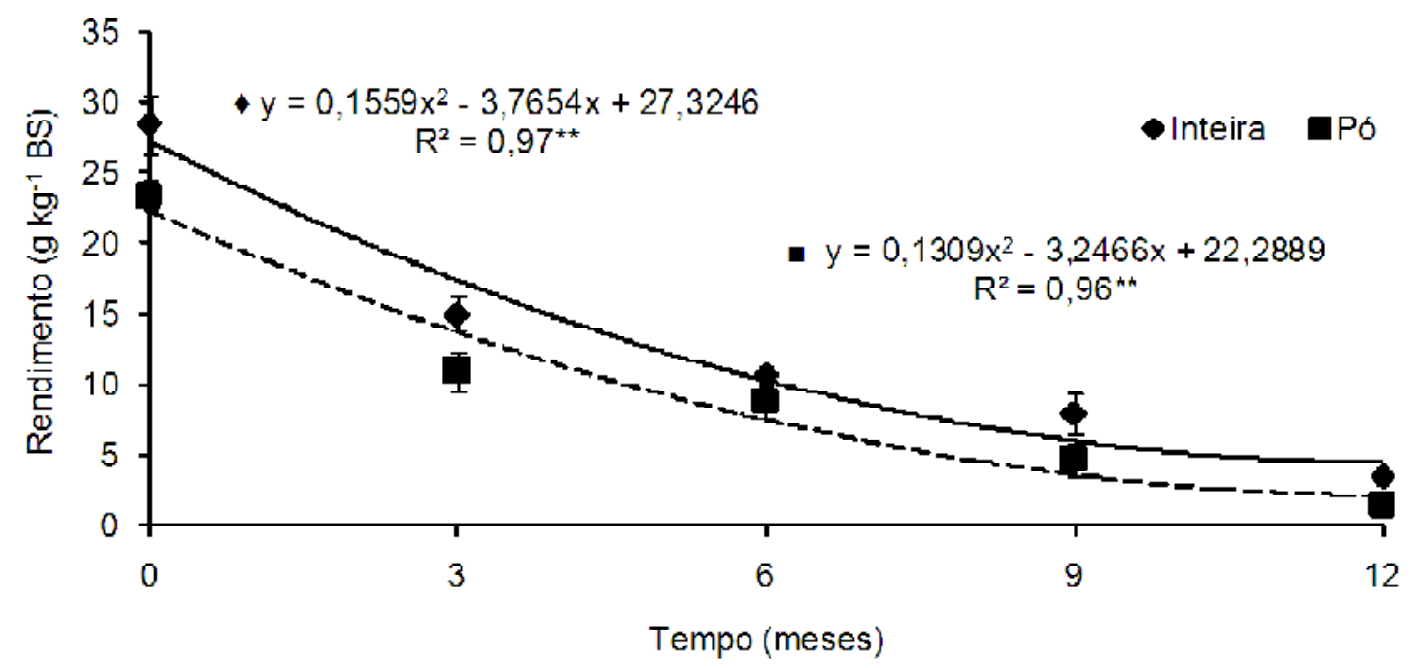

FIGURA 1. Rendimento de óleo essencial da biomassa seca de folhas de Ocimum selloi inteiras e pulverizadas, em função do tempo de armazenamento.

o rendimento de óleo essencial. Após um ano as perdas no rendimento atingiram $87,5 \%$ para as folhas inteiras e $93,8 \%$ para as folhas moídas (Figura 1 ). Resultados similares foram registrados para Tanacetum partenium, onde o tempo de armazenamento (120 dias) teve um efeito significativo na redução do teor de partenolídeos de folhas secas inteiras e moídas (Tanko et al., 2003).

Metil-chavicol (estragol), componente que apresentou maior concentração relativa nas amostras avaliadas no tempo zero $(93,98$ e 97,89, respectivamente, na matéria vegetal inteira e pó), manteve-se presente até os três meses de armazenamento, em ambos tratamentos, acima de $80 \%$. Estudos anteriores descreveram a presença de três quimiotipos desta espécie (Martins et al., 1997; Moraes etal., 2002), entre os quais umdeles apresenta similaridade química coma espécie em estudo.
De uma forma geral, durante todo o período avaliado, o metil-chavicol esteve presente com uma maior concentração relativa e melhor estabilidade química nas folhas inteiras do que nas folhas moídas, apresentando um comportamento de decréscimo ao longo do tempo de armazenamento. A forma de conservação da planta medicinal pode afetar a estabilidade química dos metabólitos secundários presentes (Gutterman \& Chauser-Volfson, 2006). Entretanto, no tempo zero de armazenamento a biomassa seca moída apresentou maior concentração relativa de metil-chavicol do que as folhas inteiras, sendo extraído isoladamente nesta condição (Tabela 1). Resposta semelhante foi observada em Cymbopogon citratus, cujo conteúdo do composto majoritário citral, também foi maior na biomassa seca em forma de pó emrelação aos fragmentos maiores (Costa et al., 2005).
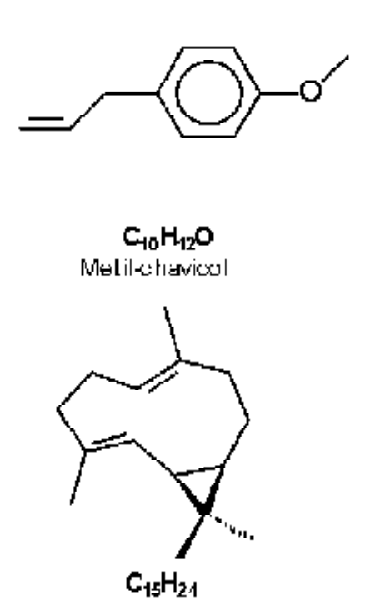

Biciclogermacreno
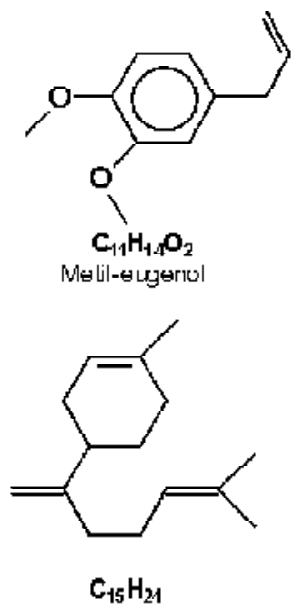

$\beta$-bisaboleno
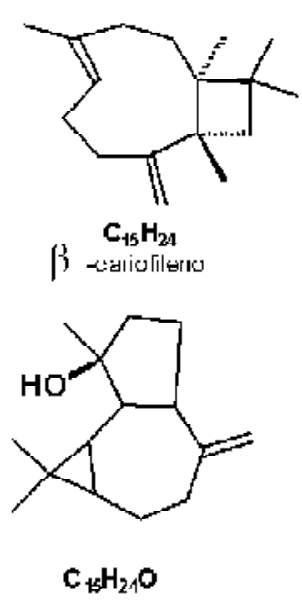

Fsnatulennl<smiles>C=C(CCC(C)C)CCC(CCC(C)C)C(C)C</smiles>

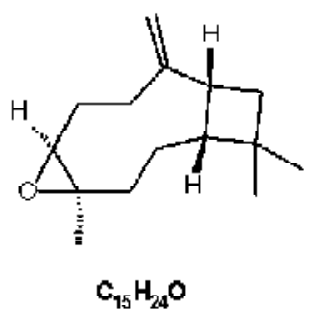

bxidn de carinfilenn

FIGURA 2. Estruturas moleculares dos principais compostos químicos presentes no óleo essencial da biomassa seca de folhas de Ocimum selloi. 
Ao final de umano, observou-se uma drástica redução na concentração relativa de metil-chavicol, o que podemos inferir que seja pela maior exposição dos componentes voláteis no material vegetal pulverizado. Simultaneamente ao declínio da concentração relativa de metil-chavicol, observou-se o aumento nas concentrações relativas de metil-eugenol, $\beta$-cariofileno, germacreno $D$, biciclogermacreno, $\beta$ bisaboleno, espatulenol e o óxido de cariofileno, presentes no óleo essencial de O. selloi ao longo do tempo de armazenamento (Figura 2). No entanto, a concentração relativa total destes componentes apresentou apenas uma pequena variação durante 0 tempo de armazenamento (Tabela 1).

O metil-chavicol teve a maior concentração relativa do óleo essencial até o nono mês de armazenamento, apresentando uma queda acentuada aos doze meses, quando foi substituído pelo biciclogermacreno na folha inteira e pelo espatulenol na folha moída (Tabela 1). Aos 9 meses de armazenamento tambémfoi possível observar uma redução mais pronunciada na concentração relativa de metil-chavicol da biomassa seca das folhas moídas em comparação com as folhas inteiras, revelando ser este tipo de fragmentação muito mais sensível à degradação.

O tipo de fragmentação e o tempo de armazenamento interferem decisivamente no rendimento e na composição do óleo essencial de O. selloi. Ocorreu uma redução acentuada no rendimento de óleo essencial da biomassa seca armazenada de folhas inteiras $(87,5 \%)$ e moídas $(93,8 \%)$ ao longo de um ano de armazenamento, mas o rendimento obtido a partir de folhas inteiras foi significativamente superior ao das folhas moídas. $\mathrm{Na}$ composição química do óleo também foi observado um declínio do composto majoritário durante o tempo de armazenamento. Amaior concentração relativa de metil-chavicol foi obtido no tempo zero de armazenamento com a biomassa seca moída onde foi extraído isoladamente.

A queda acentuada no rendimento do óleo e

TABELA 1. Concentração relativa dos picos correspondentes aos principais constituintes químicos do óleo essencial da biomassa seca de folhas de Ocimum selloi inteiras e moídas, em função do tempo de armazenamento. (IK = Índice de Kovats).

\begin{tabular}{|c|c|c|c|c|c|c|c|c|c|c|c|}
\hline \multirow{3}{*}{ Constituinte } & \multicolumn{11}{|c|}{$\begin{array}{c}\text { Tempo armazenamento (meses) } \\
\text { Concentraça relativa }(\%)\end{array}$} \\
\hline & \multicolumn{6}{|c|}{ Inteira } & \multicolumn{5}{|c|}{ Pó } \\
\hline & IK & 0 & 3 & 6 & 9 & 12 & 0 & 3 & 6 & 9 & 12 \\
\hline Metil-chavicol & 1198 & 93,9 & 92,5 & 76,6 & 64,3 & 7,2 & 97.9 & 81,4 & 61.5 & 28,8 & 1,6 \\
\hline Metile ugenol & 1397 & 0,3 & 0,7 & 1,8 & 2,2 & 5,3 & - & 1,1 & 2,3 & 5,1 & 4,7 \\
\hline$\beta$-Cariofileno & 1418 & - & 1,8 & 4,0 & 5,9 & 11,0 & - & 3,4 & 5,5 & 10,6 & 6,5 \\
\hline Germacreno D & 1480 & - & 1,6 & 4,9 & 7,1 & 18,5 & - & 3,4 & 5,8 & 11,3 & 8,9 \\
\hline Biciclogermacreno & 1494 & - & 1,9 & 6,4 & 9,7 & 28,4 & - & 3,8 & 6,4 & 13,5 & 11,8 \\
\hline$\beta$-Bisaboleno & 1506 & 0,1 & 0,3 & 0,9 & 1,3 & 3,9 & - & 0,8 & 1,7 & 4,2 & 4,1 \\
\hline Espatule nol & 1575 & 0,9 & 0,8 & 1,9 & 2,9 & 10,6 & - & 2,2 & 5,7 & 14,8 & 32,9 \\
\hline Óxido de cariofileno & 1581 & 0,9 & - & 0,3 & 0,4 & 1,4 & - & 0,3 & 1,25 & 2,7 & 6,2 \\
\hline TOTAL & & 96,4 & 99,5 & 96,8 & 93,8 & 86,4 & 97.9 & 96.5 & 90,00 & 91,1 & 76,9 \\
\hline
\end{tabular}

da concentração relativa de metil-chavicol pode ser explicada pela maior exposição dos constituintes voláteis no material pulverizado, pois nessa condição estão mais sujeitos a volatilização ou degradação. Estudos de estabilidade acelerada e de longa duração ainda precisam ser realizados com a droga vegetal, no intuito de definir seu prazo de validade e condições específicas de armazenamento.

\section{AGRADECIMENTO}

Ao Conselho Nacional de Desenvolvimento Científico e Tecnológico (CNPq) e à Fundação de Amparo à Pesquisa de Minas Gerais (FAPEMIG) pelo apoio financeiro.

\section{REFERÊNCIA}

ADAMS, R.P. Identification of essential oil components by gaschromatograpy/quadrupopole mass spectroscopy. Illinois (USA): Allured Publishing Corporation, Carol Stream 2007. 804p.

COSTA, C.C.; CASALI, V.W.D.; ANDRADE, N.J. Avaliação da droga Vernonia polyanthes L. - "Assa-peixe" obtida a partir de dois métodos de secagem e em duas épocas de coleta. Revista Brasileira de Plantas Medicinais, v.1, n.2, p.7-11, 1999a.

COSTA, C.C.; CASALI, V.W.D.; MACEDO, J.A.B. Qualidade de folhas de guaco (Mikania glomerata Sprengel) após secagem e embalagem. Revista Brasileira de Plantas Medicinais, v.1, n.2, p.1-5, $1999 \mathrm{~b}$.

COSTA, L.C.B. et al. Secagem e fragmentação da matéria seca no rendimento e composição do óleo essencial de capim-limão. Horticultura Brasileira, v.23, n.4, p.956- 
9,2005.

GRIGGS, J.K. etal. The effects of storage on the biological activity of medicinal plants from Nepal. Journal of Ethnopharmacology, v.77,p.247-52, 2001.

GUTTERMAN, Y.; CHAUSER-VOLFSON, E. Changes in secondary phenolic metabolites during storage as an aqueous suspension in comparison with the content in harvested Aloe arborescens leaves. International Journal of Food Science and Technlogy, v.41, p.662-6, 2006.

LORENZI, H.; MATOS, F.J.A. Plantas medicinais no Brasil: nativas e exóticas. Nova Odessa: Instituto Plantarum, 2003. 254p.

MARTINS, E.R. et al. Essential oil in the taxonomy of Ocimum selloi Benth. Journal of the Brazilian Chemical Society, v.8, p.29-32, 1997.

MARTINS, E.R. et al. Plantas medicinais. Viçosa: UFV, 1995. 220p

MORAES, L.A.S. et al. Phytochemical characterization of essential oil from Ocimum selloi. Anais da Academia Brasileira de Ciências, v.74,p.183-6, 2002.
PAULA, J.P.;GOMES-CARNEIRO, M.R.; PAUMGARTTEN, F.J.R. Chemical composition, toxicity and mosquito repelency of Ocimum selloi oil. Journal of Ethnopharmacology, v.88, p.253-60, 2003.

SILVA, F. et al. Qualidade pós-colheita de Achillea millefolium L., Origanum vulgare L. e Ptroselinum crispum (Miller) A.W. Hill em três embalagens. Revista Brasileira de Plantas Medicinais, v.2, n.1, p.37-41, 1999. TANKO, $\mathrm{H}$. et al. Pre- and post-harvest processing of medicinal plants. Plant Genetic Resources, v.3, n.2, p.304-13, 2005.

TANKO, $\mathrm{H}$. et al. Effects of drying temperature and storage on parthenolide concentration of feverfew (Tanacetum partenium L.) leaves. Journal of Nutraceutical, Functional and Medical Foods, v.4, n.1, p. 27-37, 2003.

VAN DEN DOOL, H.; KRATZ, P.D. Ageneralization of the retention index system including linear temperature programmed gasliquid partition chromatography. Journal of Chromatography, v.11, p.463-71, 1963. 